\title{
Impedance-Based Miniaturized Biosensor for Ultrasensitive and Fast Prostate-Specific Antigen Detection
}

\author{
Ganna Chornokur, ${ }^{1,2,3}$ Sunil K. Arya, ${ }^{1}$ Catherine Phelan, ${ }^{2,3}$ Richard Tanner, ${ }^{2}$ \\ and Shekhar Bhansali ${ }^{1}$ \\ ${ }^{1}$ BioMEMS and Microsystems Laboratory, University of South Florida, 4202 East Fowler Avenue, Tampa, FL 33620, USA \\ ${ }^{2}$ Moffitt Cancer Center and Research Institute, 12902 Magnolia Dr., Tampa, FL 33612, USA \\ ${ }^{3}$ The Center for Equal Health, University of South Florida, Tampa, FL 33612, USA
}

Correspondence should be addressed to Shekhar Bhansali, bhansali@usf.edu

Received 8 September 2010; Accepted 25 January 2011

Academic Editor: Michele Penza

Copyright (C) 2011 Ganna Chornokur et al. This is an open access article distributed under the Creative Commons Attribution License, which permits unrestricted use, distribution, and reproduction in any medium, provided the original work is properly cited.

This paper reports the successful fabrication of an impedance-based miniaturized biosensor and its application for ultrasensitive Prostate-Specific Antigen (PSA) detection in standard and real human plasma solution, spiked with different PSA concentrations. The sensor was fabricated using photolithographic techniques, while monoclonal antibodies specific to human PSA were used as primary capture antibodies. Electrochemical impedance spectroscopy (EIS) was employed as a detection technique. The sensor exhibited a detection limit of $1 \mathrm{pg} / \mathrm{ml}$ for PSA with minimal nonspecific binding (NSB). This detection limit is an order of magnitude lower than commercial PSA ELISA assays available on the market. The sensor can be easily modified into an array for the detection of other biomolecules of interest, enabling accurate, ultrasensitive, and inexpensive point-of-care sensing technologies.

\section{Introduction}

Prostate cancer is one of the most widespread cancerous malignancies amongst the male population in the United States [1]. Prostate cancer is the second leading cause (after lung cancer) for all cancer-related deaths amongst males. On average, males in the United States have 1:6 odds of being diagnosed with prostate cancer during their lifetime [2]. Currently, there are only two approved prostate cancer screening methods: Digital Rectal Examination (DRE) and Prostate-Specific Antigen (PSA) blood test [3]. DRE, however, possesses low sensitivity and is a function of the skills of the doctor conducting the examination. Additionally, due to hesitation amongst males to undergo the "invasive" exam and variability in the skill levels of the doctors, DRE in many instances leads to the diagnosis of advanced noncurable tumors [4]. Hence, clinicians are increasingly turning to less invasive blood-based diagnostics tests (e.g., serum PSA), which [3] have led to tremendous improvements in early detection and reduced prostate cancer-related mortality and morbidity [5]. The epidemiological importance of prostate cancer therefore warrants a faster, cheaper, and more accurate sensing device for the PSA-based prostate cancer screening and detection.

The generally accepted technique for PSA detection is Enzyme-Linked Immuno Assay (ELISA). However, ELISA and its variations have a detection limit in the highpicomolar ranges. Detection techniques which employ chromatography principle, while offering potentially lower detection limits, are expensive, laborious, and time intensive and are not suited to both routine screening applications and point-of-care diagnostics [6]. As a response to the need for better and sensitive detection methods, numerous novel detection techniques have recently emerged [7]. A proposed alternative to conventional ELISAs is the use of nanoparticles, which has shown promise to achieve lowered detection limits $[8,9]$. These methods, however, share some of the drawbacks of chromatography: increased cost, labor, and analysis time. In addition, the inability to reliably estimate a number of nanoparticles attached to one detector biomolecule has made it difficult to quantify the results. 
Electrochemical biosensors constitute a promising group of sensing devices that allow increased sensitivities, low cost, low analysis times, affordability, and miniaturized platforms [10-17]. There are numerous electrochemical techniques currently being researched towards applications in biosensors, which are described in detail elsewhere [18-27]. Among them, Electrochemical Impedance Spectroscopy(EIS-) based detection is gaining significant interest as a label-free technique for sensitive measurement of target analytes [28]. EIS is a powerful and sensitive technique used to characterize surface-modified electrodes and for the investigation of electrochemical systems and processes [29]. It uses periodic small AC amplitudes and responds to signal change caused by the binding of target analytes to primary antibodies immobilized on the surface of the electrodes [30,31].

This paper reports successful development of an impedance-based miniaturized biosensor for PSA detection. The biosensor exhibited a detection limit of $1 \mathrm{pg} / \mathrm{ml}$ for PSA in human plasma. This sensitivity is an order of magnitude lower than the most sensitive commercial ELISA on the market [32]. Average detection time with the sensor for one sample is around 45 minutes, compared to at least 2.5 hours for a standard ELISA [32]. This research has also addressed and minimized the issue of nonspecific binding (NSB).

\section{Materials and Methods}

2.1. Chemicals and Reagents. Dithiobis(succinimidyl propionate) (DTSP) and sodium borohydride $\left(\mathrm{NaBH}_{4}\right)$ were purchased from ThermoFisher Scientific. Purified PSA protein (product \# 7820-0604), Monoclonal PSA antibody (anti-PSA, Mab, product \# 7820-0217), and monoclonal cortisol antibody (product \# 2330-4839) were procured from Abd Serotec. Phosphate buffered saline (PBS) tablets were purchased from Sigma Aldrich. SU-8 50 resist was purchased from Microchem Corp. Blocking buffers (general low-level BB1 and Neptune Block BB2) were obtained from Immunochemistry Technologies, LLC. All other chemicals were of analytical grade and were used without further purification. PBS solution $(10 \mathrm{mM}, \mathrm{pH} 7.4)$ was prepared by dissolving 1 tablet in $200 \mathrm{ml}$ of deionized water. Working solutions of PSA, anti-PSA, and anticortisol were prepared by dilution in PBS (10 mM, pH 7.4).

2.2. PSA Sample Collection and Storage. Human serum and plasma samples, collected at Moffitt Cancer Center and participating clinics, were used in this study. The study was approved by an Institutional Review Board (IRB), and informed consent was obtained from all participants prior to a blood draw. The deidentified samples were obtained from African-American males with clinically diagnosed Prostate cancer (cases), and with no clinical evidence of Prostate cancer (controls). Samples were labeled, aliquoted, and stored at deep freezer $\left(-80^{\circ} \mathrm{C}\right)$ until further usage according to the Moffitt Cancer Center guidelines [33]. None of the samples have undergone more than 2 freeze-thaw cycles. All samples were tested for PSA in triplicates using commercial ELISA kit and the values were recorded.
2.3. Measurement and Apparatus. Electrochemical impedance spectroscopy (EIS) was utilized to characterize the EA/Anti-PSA/DTSP/ID $\mu$ E bioelectrode and to estimate PSA concentration. EIS measurements were carried out at equilibrium potential without external biasing in the frequency range of $0.5-10^{5} \mathrm{~Hz}$ with a $5 \mathrm{mV}$ amplitude using Autolab Potentiostat/Galvanostat (Eco Chemie, Netherlands). EIS measurements were carried out using $65 \mu \mathrm{l}$ of PBS solution $(10 \mathrm{mM}, \mathrm{pH} 7.4)$ containing a mixture of $5 \mathrm{mM} \mathrm{Fe}(\mathrm{CN})_{6}^{4-}$ (Ferrocyanide) and $5 \mathrm{mM}$ of $\mathrm{Fe}(\mathrm{CN})_{6}^{3-}$ (Ferricyanide) that is $5 \mathrm{mM} \mathrm{Fe}(\mathrm{CN})_{6}^{3-/ 4-}$ as a redox probe. In present studies, Nyquist plots have been utilized to study the change in charge transfer resistance $\left(R_{\mathrm{ct}}\right)$ at sensor-solution interfaces with changing concentration of PSA.

2.4. Test Chip Fabrication. The Biosensor test chips were fabricated on an oxidized $4^{\prime \prime}$ silicon wafer using standard photolithography techniques, as described previously [34, 35]. Briefly, Cr/Au (200/2000 §) layers were deposited using e-beam evaporation and were patterned through lift-off (Figure $1(\mathrm{a})$ ). ID $\mu \mathrm{E}$ with $5 \mu \mathrm{m}$ wide electrode fingers and with a pitch of $10 \mu \mathrm{m}$ were used in this work. As a final step, an SU8 chamber was patterned around the electrodes using the SU8 50 resist to create a sample well around these electrodes, and hard baked at $200^{\circ} \mathrm{C}$ to improve its resistance against hard solvents like acetone. Figure 1(b) shows the actual photograph of a Biosensor reagent chamber under optical microscope (10x).

2.5. Self-Assembled Monolayer (SAM) Preparation and Antibody Immobilization. The process was conducted as described previously $[35,36]$. Briefly, the Biosensor chips were precleaned with acetone, isopropyl alcohol, and deionized water, and exposed to $2 \mathrm{mg} / \mathrm{ml}$ solution of DTSP in acetone for $1 \mathrm{hr}$ for SAM formation. DTSP solution was first reduced using $\mathrm{NaBH}_{4}$ and then dispensed on the precleaned chips at room temperature. The DTSP SAM modified electrodes were then rinsed with acetone to remove any unbound DTSP followed by rinsing in water. The electrodes were then utilized for antibody immobilization. PSA antibodies were covalently attached to DTSP self-assembled monolayer by incubating the electrode in $65 \mu \mathrm{l}$ of $1 \mu \mathrm{g} / \mathrm{ml}$ antibody in PBS solution (10 mM, pH 7.4) for $1 \mathrm{hr}$. Covalent binding (amide bond formation) results from the reaction between amino group of antibody and reactive succinimidyl group of the DTSP on the SAM surface. The sensor (AntiPSA/DTSP/ID $\mu$ E) was washed thoroughly with PBS $(10 \mathrm{mM}$, $\mathrm{pH}$ 7.4) to remove any unbound biomolecules followed by a 10-minute washing with ethanolamine (EA) (1\%). EA was used to block any unreacted succinimidyl groups on DTSP SAM and to remove extra unbound antibodies onto the electrode surface. Figure 2 schematically illustrates (a) $\mathrm{ID} \mu \mathrm{E}$ chip, (b) step-by-step immunochemical reaction on the electrode surfaces, and (c) proposed detection system. The fabricated detection limits were characterized using electrochemical impedance technique. Each sample was run in triplicates to ensure reproducibility, and an average result of three runs was used. 


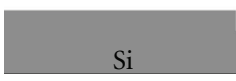

(a)

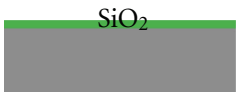

(b)

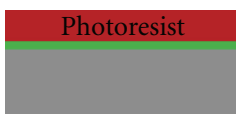

(c)

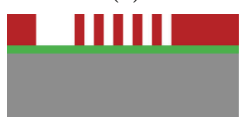

(d)

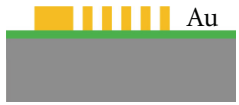

(e)

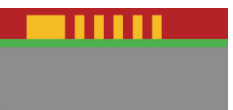

(f)

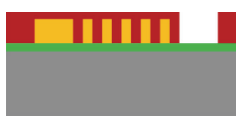

(g)

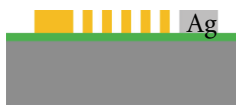

(h)

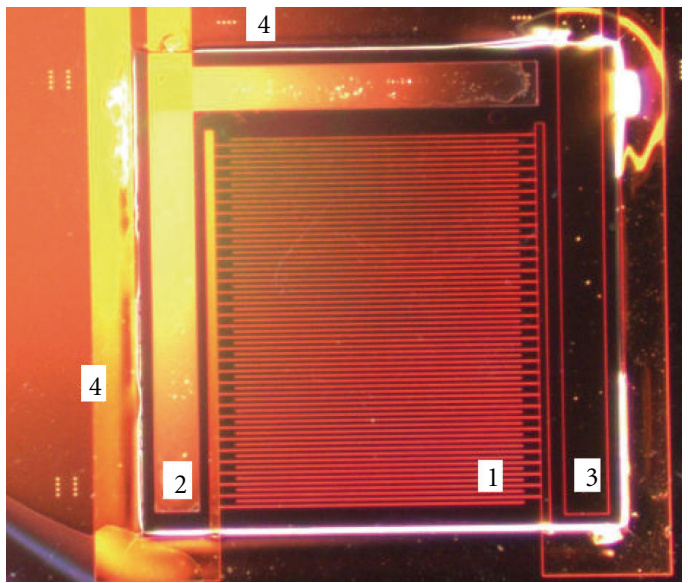

(B)

(A)

Figure 1: (A) Biosensor fabrication process flow: (a) RCA clean Si wafer, (b) thermal oxidation to grow $500 \mathrm{~nm} \mathrm{SiO}_{2}$ as an insulation layer, (c) apply photoresist, (d) expose and pattern photoresist, (d) deposit Au using electron beam (e-beam) evaporator with a thickness of $200 \mathrm{~nm}$ and lift-off photoresist to get patterned Au electrodes, (f) apply photoresist, (g) pattern photoresist, and (h) finally deposit Ag using e-beam evaporator with thickness of $200 \mathrm{~nm}$ and lift-off is used to remove photoresist and excess metal on top of it. (B) Biosensor actual view under a microscope (10x): (1) gold working interdigitated electrodes; (2) silver pseudoreference electrode; (3) gold counter electrode; and (4) SU8 reagent chamber.

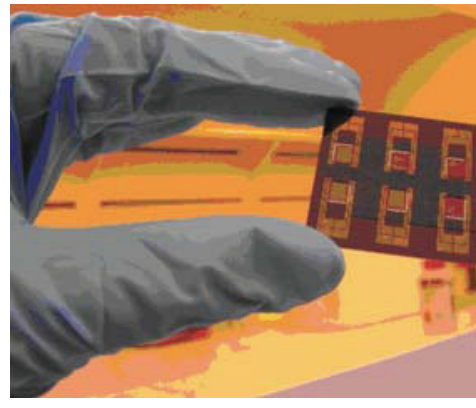

(a)

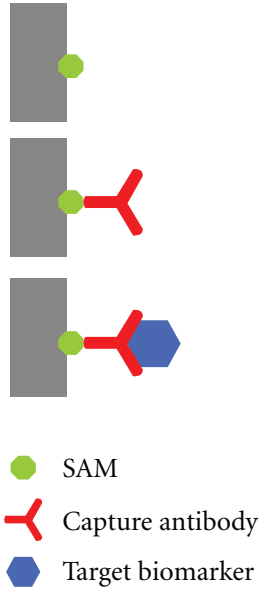

(b)

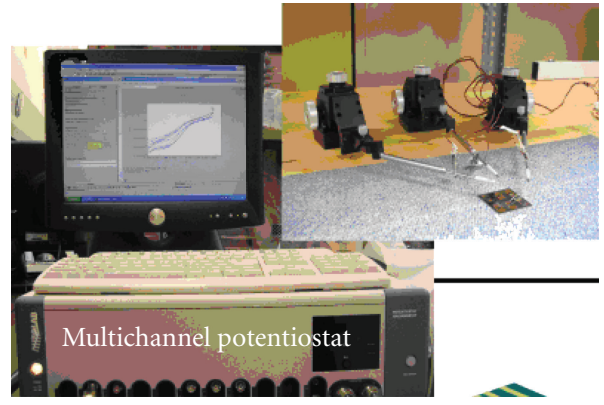

(c)

Figure 2: Biosensor. (a) Testing chambers with patterned microelectrodes on Si substrate (6 reagent chambers incorporated into one platform); (b) brief schematic illustration of step-by-step immunochemical reaction on the electrode surfaces; (c) proposed detection system. The multichannel potentiostat is used to scan each reaction chamber on Biosensor.

It is noteworthy, that due to the small size of the $\mathrm{ID} \mu \mathrm{E}$ chip, any change in the sample volume or in the nature of the solutions or dielectric properties of material may affect the results of sensing. Therefore, in the present work, all experiments were carried out under identical conditions of solution volume and materials, and change in charge transfer resistance (difference of before and after external incubation of PSA concentration) for PBS containing $\mathrm{Fe}(\mathrm{CN})_{6}^{3-14-}$ (measurement buffer) was measured for PSA estimation. As all the conditions were kept identical during EIS measurement and change in signal was used for estimation, the factors such as solution volume or material get cancelled. Hence, the change in the EIS signal is attributed solely to changing PSA concentration which on interaction with surface bound antibody results in formation of the insulating layer on the surface, thus causing increase of charge transfer resistance for measuring buffer.

\section{Results and Discussion}

3.1. Biosensor Testing with the PSA Solutions in PBS. Biosensor was first utilized to detect PSA molecules in PBS in 


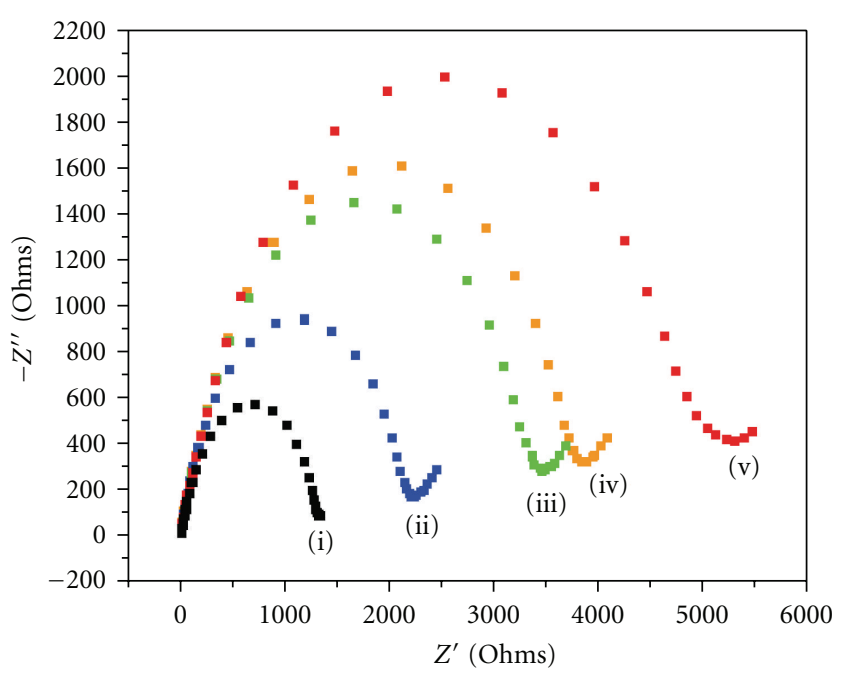

(a)

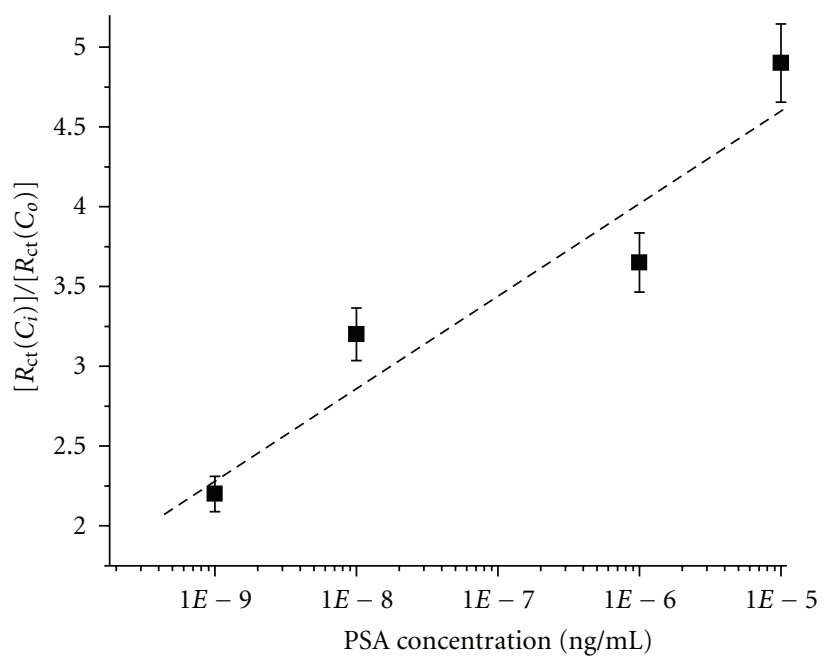

(b)

FIgURE 3: Initial test with PSA concentrations in PBS. (a) EIS spectra for: (i) buffer, (ii) $1 \mathrm{pg} / \mathrm{ml}$, (iii) $10 \mathrm{pg} / \mathrm{ml}$, (iv) $1 \mathrm{ng} / \mathrm{ml} \mathrm{and}$ (v) $10 \mathrm{ng} / \mathrm{ml}$; (b) normalized standard curve for data shown in the Figure 3(a).

the concentration range $1 \mathrm{pg} / \mathrm{ml}-10 \mathrm{ng} / \mathrm{ml}$ (Figure $3(\mathrm{a})$ ). This range was chosen empirically, based on the interest for meeting both current needs in PSA sensitivity (usually up to $10 \mathrm{ng} / \mathrm{ml}$ in clinics) and establishing the lower detection limit. For each concentration, the EA/Anti-PSA/DTSP/ID $\mu \mathrm{E}$ bioelectrode was incubated in PSA solution for 30 minutes, followed by PBS washing and EIS spectra recording using PBS $(10 \mathrm{mM}, \mathrm{pH} 7.4)$ containing $5 \mathrm{mM} \mathrm{Fe}(\mathrm{CN})_{6}^{3-/ 4-}$ as a redox probe. From Figure $3(\mathrm{a})$, it is clear that $R_{\mathrm{ct}}$ (diameter of the Nyquist plots) increased with increasing PSA concentration. The increase in $R_{\mathrm{ct}}$ is attributed to the binding of PSA to immobilized anti-PSA on EA/AntiPSA/DTSP/ID $\mu$ E bioelectrode, producing a barrier layer that inhibits the charge transfer for a redox probe, as relative change in EIS data has more significant information than absolute value for sensing applications. The change in $R_{\mathrm{ct}}$ was used for calibration. A plot of the change in $R_{\mathrm{ct}}$ values and the logarithm of PSA concentrations reveal a linear detection range for PSA concentrations in the range of $1 \mathrm{pg} / \mathrm{ml}$ to $10 \mathrm{ng} / \mathrm{ml}$ (data not shown). A calibration curve for normalized data is shown on the Figure 3(b).

Due to lack of industrial level controls during microfabrication and chemical activity, variations in impedance of individual electrodes and antibody modified electrodes were observed. Therefore, to confirm that the observed change in impedance was due to surface modification and not due to superimposed effects, the data was normalized to charge transfer resistance for desired concentration $\left[\left(R_{\mathrm{ct}}\left(C_{i}\right)\right)\right] /[$ charge transfer resistance of blank EA/AntiPSA/DTSP/ID $\mu$ E bioelectrode $\left.\left(R_{\mathrm{ct}}\left(C_{o}\right)\right)\right]$. In Figure 3(b), plot of $\left(R_{\mathrm{ct}}\left(C_{i}\right)\right) /\left(R_{\mathrm{ct}}\left(C_{o}\right)\right)$ versus the logarithm of cortisol concentration shows the results of triplicate set. After normalization, all electrodes with different impedances for detection limits with attached antibodies exhibited similar response within the $4 \%$ error for each concentration. The normalized data curve (Figure 3(b)) can be characterized using a linear relation; $R_{\mathrm{ct}}\left(C_{i}\right) / R_{\mathrm{ct}}\left(C_{o}\right)=7.50+0.579 \log C_{\mathrm{PSA}}$. It reveals the linear range of $1 \mathrm{pg} / \mathrm{ml}$ to $10 \mathrm{ng} / \mathrm{ml}$ with the detection limit of $1 \mathrm{pg} / \mathrm{ml}$ and correlation coefficient of 0.959 . Further, to account for the variation in initial impedance values of individual electrodes and to avoid superimposed effects of multielectrode measurement, all experiments were carried out using a step-by-step approach to increase PSA concentration. Similar step-by-step concentration studies have been reported by other researchers and help avoid superimposed effects of multielectrode measurement [37-42].

As is seen from Figure 3(b), the correlation coefficient for the calibration curve is 0.959 , suggesting a relatively weak linear trend. This effect can be attributed to the interfering effects of Nonspecific binding (NSB) which is a common obstacle in all bioassays, employing immunological affinity principles. In this study, general BSA-based (BB1) and increased strength nonmammalian proteinsbased (BB2) blocking buffers and 30 to 60 min blocking times were studied. However, no significant change in NSB interference was observed with the introduction of different blocking techniques or extra strength blocking buffers (data not shown). To handle NSB issues in a better way, new experiments with diluted serum as blocking were designed and performed.

3.2. Human Plasma Testing with Biosensor. It was hypothesized that a human plasma sample, even when substantially diluted, will have enough proteins to block the initial electrode and can minimize subsequent NSB during bioassays. Hence, in order to address the NSB issues, a real plasma sample with very low PSA concentration of $0.4 \mathrm{ng} / \mathrm{ml}$ was diluted 1000 times with PBS. This solution was then used as a diluent for the rest of the experiments. The level of PSA in the diluents was an order of magnitude lower than the concentration of PSA in samples, thus ensuring that diluent PSA does not interfere with sample PSA detection. 


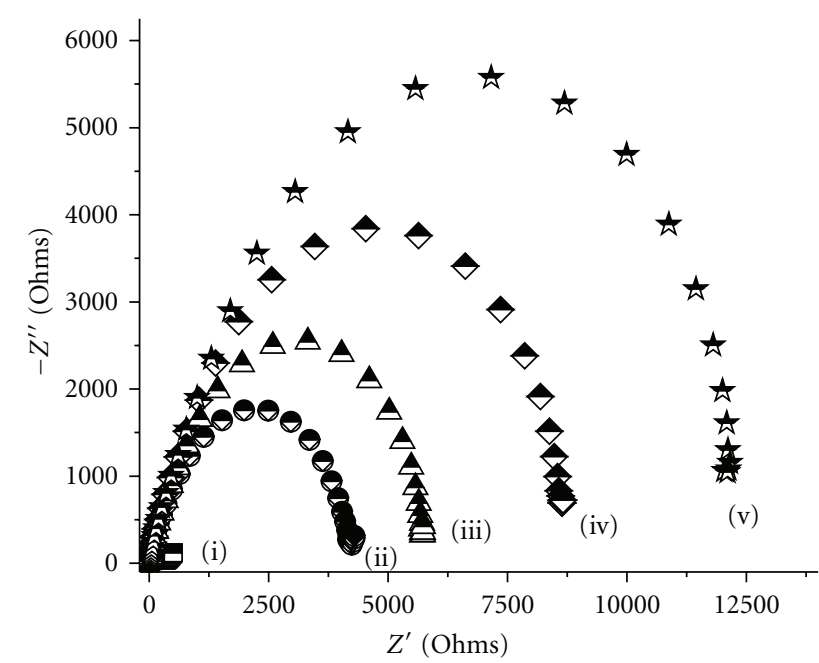

FIgURE 4: Impedance spectra for PSA sensing in human plasma sample for concentration (i) buffer, (ii) diluent $(0.4 \mathrm{pg} / \mathrm{ml})$, (iii) $1.4 \mathrm{pg} / \mathrm{ml}$, (iv) $10.4 \mathrm{pg} / \mathrm{ml}$ and (v) $100.4 \mathrm{pg} / \mathrm{ml}$.

It was observed that the use of diluent and blocker masked major NSB issues and established that sensors can be used with human serum samples without a loss in sensitivity and selectivity. To perform the experiments, diluent was subsequently spiked with different PSA concentrations. Based on previous results (Figure 3), 1; 10 and $100 \mathrm{pg} / \mathrm{ml}$ of PSA were chosen as initial testing points. Knowing that PSA concentration in the diluent was $0.4 \mathrm{pg} / \mathrm{ml}$, the actual PSA values in the samples were $0.4,1.4,10.4$, and $100.4 ; \mathrm{pg} / \mathrm{ml}$.

The testing was carried out in the same low to high concentration order as described earlier for standard PSA solutions. The results shown in Figure 4 reveal a clear dependence of the impedance resistance with increasing PSA concentration, indicating PSA binding. Each step was resumed after PBS washing to ensure complete removal of unbound molecules.

It is important to note that due to a pilot nature of this work, no formal statistical analysis was performed. The overall testing procedures with Biosensor were as follows: (1) SAM formation on gold electrode; (2) anti-PSA incubation + wash + impedance reading; (3) base solution ("blocker", $0.4 \mathrm{pg} / \mathrm{ml}$ PSA) incubation + wash + reading; (4) $1 \mathrm{pg} / \mathrm{ml}$ incubation + wash + reading; (5) $10 \mathrm{pg} / \mathrm{ml}$ incubation + wash + reading; (6) $100 \mathrm{pg} / \mathrm{ml}$ incubation + wash + reading.

Figure 5 presents the calibration curve for data obtained from Figure 4 where before first run bioelectrode was treated and blocked with diluent and it is clear from Figure 5 that there is a strong linear concentration dependence on the impedance increase in resistance with increased PSA concentration. The correlation coefficient for this experiment was found to be 0.995 , indicating strong linear dependence. The normalized data curve (Figure 5) can be characterized using $R_{\mathrm{ct}}\left(C_{i}\right) / R_{\mathrm{ct}}\left(C_{o}\right)=5.50+3.458 \log C_{\mathrm{PSA}}$.

3.3. Selectivity Studies. Selectivity is a major and well-known pitfall in biosensing techniques. To ensure the selectivity of

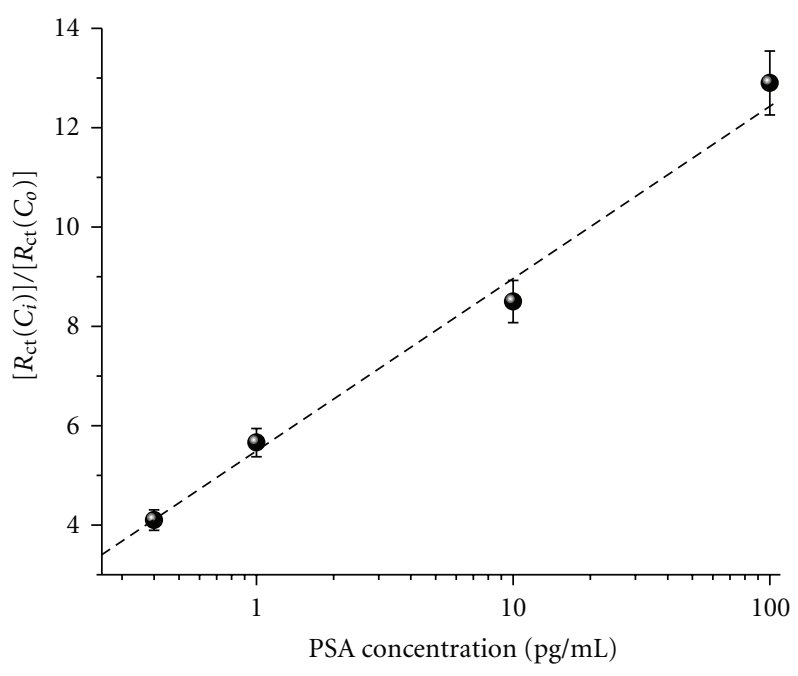

FIGURE 5: Normalized curve for data obtained from EIS studies for different PSA concentrations with 1000 times diluted human plasma as blocker and diluent.

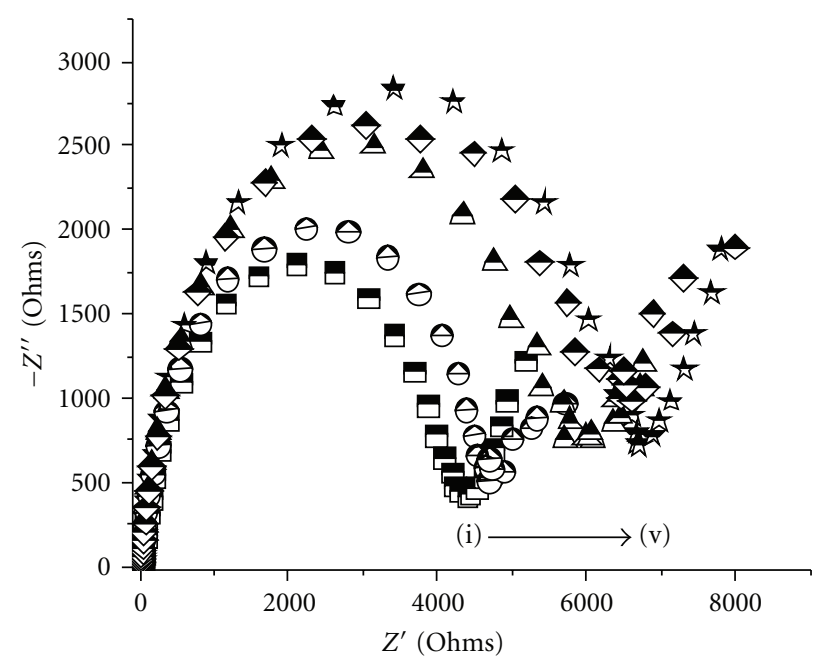

Figure 6: The interference studies of EA/Anti-PSA/DTSP/ID $\mu \mathrm{E}$ bioelectrode using anti-cortisol as interfering protein at concentration (i) buffer, (ii) $1 \mathrm{pg} / \mathrm{ml}$, (iii) $10 \mathrm{pg} / \mathrm{ml}$, (iv) $100 \mathrm{pg} / \mathrm{ml}$, and (v) $1000 \mathrm{pg} / \mathrm{ml}$.

PSA binding, increasing concentrations of cortisol antibody solutions in PBS were tested on the electrodes functionalized with captured anti-PSA. Anti-cortisol was selected as a random protein which can contribute to nonselective binding with $0 ; 1 ; 10 ; 100$ and $1000 \mathrm{pg} / \mathrm{ml}$ solutions of anti-cortisol in PBS. The testing was done in identical conditions. Ideally, no increase in resistance should be observed if NSB is completely absent. The results shown in Figure 6 reveal a slight increase in resistance with increasing anti-cortisol concentrations. However, the observed change is very low as compared to PSA (15.5\% highest increase compared to $312 \%$ increase for lowest PSA concentration), indicating that NSB is in fact present although negligibly small. 


\section{Conclusions}

It has been shown that the EA/Anti-PSA/DTSP/ID $\mu \mathrm{E}$ bioelectrode-based, impedimetric electrochemical immunosensor, can be used for ultrasensitive and selective PSA detection. EA/Anti-PSA/DTSP/ID $\mu \mathrm{E}$ bioelectrode exhibits linear behavior in the concentration range of $1 \mathrm{pg} / \mathrm{ml}$ to $100 \mathrm{pg} / \mathrm{ml}$ with detection limit of $1 \mathrm{pg} / \mathrm{ml}$. This detection limit is an order of magnitude lower than the most sensitive commercially available PSA ELISA kit on the market. The average analysis time of 45 minutes is shorter than commercial ELISA (at least $2.5 \mathrm{hrs}$ ). The usage of diluted plasma sample as a diluent and blocker allowed masking of major NSB issues. The sensor was found to be selective against cortisol antibody in the concentrations $1-1000 \mathrm{pg} / \mathrm{ml}$ and was tested as a proof of concept with the human plasma sample, spiked with increasing PSA concentrations. The same principle could be applied for the detection of other biomolecules of interest.

\section{Acknowledgments}

This work was partially supported through NSF Award 0700659 Nanoengineered, Manufacturable, IonImplantation Seeded Silica Nanowires for Sensitive BioScreening, UFMoffitt Pilot Award Prostate Cancer Biomarker Study in African American Men; BiTT Award: An Automated Cell Health Monitoring System (CHMS) Based on Electrical Impedance; the National Institute of Health-NIH 1 P20 MD003375-01.

\section{References}

[1] National Cancer Institute Official, http://www.cancer.gov.

[2] Surveillance Epidemiology and End Results, http://www.seer .cancer.gov.

[3] T. Steuber, M. F. O’Brien, and H. Lilja, "Serum markers for prostate cancer: a rational approach to the literature," European Urology, vol. 54, no. 1, pp. 31-40, 2008.

[4] W. H. Cooner, B. R. Mosley, C. L. Rutherford et al., "Prostate cancer detection in a clinical urological practice by ultrasonography, digital rectal examination and prostate specific antigen. 1990," Journal of Urology, vol. 167, no. 2, pp. 966-973, 2002.

[5] F. H. Schröder, J. Hugosson, M. J. Roobol et al., "Screening and prostate-cancer mortality in a randomized european study," New England Journal of Medicine, vol. 360, no. 13, pp. 1320$1328,2009$.

[6] M. C. McMaster, HPLC, a Practical User's Guide, WileyInterscience, New York, NY, USA, 2nd edition, 2007.

[7] A. J. Qavi, A. L. Washburn, JI. Y. Byeon, and R. C. Bailey, "Label-free technologies for quantitative multiparameter biological analysis," Analytical and Bioanalytical Chemistry, vol. 394, no. 1, pp. 121-135, 2009.

[8] G. Chornokur, S. Ostapenko, E. Oleynik et al., "Scanning photoluminescent spectroscopy of bioconjugated quantum dots," Superlattices and Microstructures, vol. 45, no. 4-5, pp. 240-248, 2009.

[9] K. Kerman, T. Endo, M. Tsukamoto, M. Chikae, Y. Takamura, and E. Tamiya, "Quantum dot-based immunosensor for the detection of prostate-specific antigen using fluorescence microscopy," Talanta, vol. 71, no. 4, pp. 1494-1499, 2007.
[10] M. Pumera, S. Sánchez, I. Ichinose, and J. Tang, "Electrochemical nanobiosensors," Sensors and Actuators B, vol. 123, no. 2, pp. 1195-1205, 2007.

[11] M. Tudorache and C. Bala, "Biosensors based on screenprinting technology, and their applications in environmental and food analysis," Analytical and Bioanalytical Chemistry, vol. 388, no. 3, pp. 565-578, 2007.

[12] C. Dhand, S. K. Arya, M. Datta, and B. D. Malhotra, "Polyaniline-carbon nanotube composite film for cholesterol biosensor," Analytical Biochemistry, vol. 383, no. 2, pp. 194199, 2008.

[13] A. Kumar, S. Aravamudhan, M. Gordic, S. Bhansali, and S. S. Mohapatra, "Ultrasensitive detection of cortisol with enzyme fragment complementation technology using functionalized nanowire," Biosensors and Bioelectronics, vol. 22, no. 9-10, pp. 2138-2144, 2007.

[14] S. M. Radke and E. C. Alocilja, "A high density microelectrode array biosensor for detection of E. coli O157:H7," Biosensors and Bioelectronics, vol. 20, no. 8, pp. 1662-1667, 2005.

[15] T. Bolaño, R. Castarlenas, M. A. Esteruelas, and E. Oñate, "Assembly of an allenylidene ligand, a terminal alkyne, and an acetonitrile molecule: formation of osmacyclopentapyrrole derivatives," Journal of the American Chemical Society, vol. 128, no. 12, pp. 3965-3973, 2006.

[16] S. Alegret, Integrated Analytical Systems, vol. 39, chapter 1, Elsevier, Amsterdam, The Netherlands, 2003.

[17] S. K. Arya, P. R. Solanki, R. P. Singh, M. K. Pandey, M. Datta, and B. D. Malhotra, "Application of octadecanethiol self-assembled monolayer to cholesterol biosensor based on surface plasmon resonance technique," Talanta, vol. 69, no. 4, pp. 918-926, 2006.

[18] K. Oka, M. Noguchi, T. Kitamura, and S. Shima, "Liquid chromatography and radioimmunoassay compared for determination of cortisol and corticosterone in plasma after a dexamethasone suppression test," Clinical Chemistry, vol. 33, no. 9, pp. 1639-1642, 1987.

[19] D. Appel, R. D. Schmid, C. A. Dragan, M. Bureik, and V. B. Urlacher, "A fluorimetric assay for cortisol," Analytical and Bioanalytical Chemistry, vol. 383, no. 2, pp. 182-186, 2005.

[20] R. Gatti, E. Cappellin, B. Zecchin et al., "Urinary high performance reverse phase chromatography cortisol and cortisone analyses before and at the end of a race in elite cyclists," Journal of Chromatography B, vol. 824, no. 1-2, pp. 51-56, 2005.

[21] I. Jerkunica, J. Sophianopoulos, and D. Sgoutas, "Improved ultrafiltration method for determining unbound cortisol in plasma," Clinical Chemistry, vol. 26, no. 12, pp. 1734-1737, 1980.

[22] M. Vogeser, P. Möhnle, and J. Briegel, "Free serum cortisol: quantification applying equilibrium dialysis or ultrafiltration and an automated immunoassay system," Clinical Chemistry and Laboratory Medicine, vol. 45, no. 4, pp. 521-525, 2007.

[23] N. J. Cook, A. L. Schaefer, P. Lepage, and S. D. Morgan Jones, "Radioimmunoassay for cortisol in pig saliva and serum," Journal of Agricultural and Food Chemistry, vol. 45, no. 2, pp. 395-399, 1997.

[24] D. Schmalzing, W. Nashabeh, X. W. Yao et al., "Capillary electrophoresis-based immunoassay for cortisol in serum," Analytical Chemistry, vol. 67, no. 3, pp. 606-612, 1995.

[25] W. A. Kaptein, J. J. Zwaagstra, K. Venema, M. H. J. Ruiters, and J. Korf, "Analysis of cortisol with a flow displacement immunoassay," Sensors and Actuators B, vol. 45, no. 1, pp. 6369, 1997. 
[26] M. Sarkar, B. C. Das, B. D. Bora et al., "Application of sensitive enzymeimmunoassay for determination of cortisol in blood plasma of yaks (Poephagus grunniens L.)," General and Comparative Endocrinology, vol. 154, no. 1-3, pp. 85-90, 2007.

[27] J. S. Mitchell, T. E. Lowe, and J. R. Ingram, "Rapid ultrasensitive measurement of salivary cortisol using nano-linker chemistry coupled with surface plasmon resonance detection," Analyst, vol. 134, no. 2, pp. 380-386, 2009.

[28] A. J. Bard, M. Stratmann, and P. R. Unwin, Instrumentation and Electroanalytical Chemistry, vol. 3, chapters 1-2, WileyVCH, New Jersey, NJ, USA, 2003.

[29] E. Barsoukov and J. R. MacDonald, Impedance Spectroscopy: Theory, Experiment and Applications, chapter 1, WileyInterscience, New Jersey, NJ, USA, 2nd edition, 2005.

[30] J. G. Guan, YU. Q. Miao, and Q. J. Zhang, "Impedimetric biosensors," Journal of Bioscience and Bioengineering, vol. 97, no. 4, pp. 219-226, 2004.

[31] A. W. Bott, "Electrochemical techniques for the characterization of redox polymers," Current Separations, vol. 19, no. 3, pp. 71-75, 2001.

[32] http://www.biokits.com.

[33] Moffitt Cancer Center and Research Institute Official, http:// www.moffitt.org.

[34] KE. Sun, N. Ramgir, and S. Bhansali, "An immunoelectrochemical sensor for salivary cortisol measurement," Sensors and Actuators B, vol. 133, no. 2, pp. 533-537, 2008.

[35] S. K. Arya, G. Chornokur, M. Venugopal, and S. Bhansali, "Dithiobis(succinimidyl propionate) modified gold microarray electrode based electrochemical immunosensor for ultrasensitive detection of cortisol," Biosensors and Bioelectronics, vol. 25, no. 10, pp. 2296-2301, 2010.

[36] S. K. Arya, G. Chornokur, M. Venugopal, and S. Bhansali, "Antibody functionalized interdigitated $\mu$-electrode (ID $\mu \mathrm{E}$ ) based impedimetric cortisol biosensor," Analyst, vol. 135, no. 8, pp. 1941-1946, 2010.

[37] R. C. Stevens, S. D. Soelberg, S. Near, and C. E. Furlong, "Detection of cortisol in saliva with a flow-filtered, portable surface plasmon resonance biosensor system," Analytical Chemistry, vol. 80, no. 17, pp. 6747-6751, 2008.

[38] R. Maalouf, C. Fournier-Wirth, J. Coste et al., "Labelfree detection of bacteria by electrochemical impedance spectroscopy: comparison to surface plasmon resonance," Analytical Chemistry, vol. 79, no. 13, pp. 4879-4886, 2007.

[39] X. L. Su and Y. Li, "A self-assembled monolayer-based piezoelectric immunosensor for rapid detection of Escherichia coliO157:H7," Biosensors and Bioelectronics, vol. 19, no. 6, pp. 563-574, 2004.

[40] Y. Huang, M. C. Bell, and I. I. Suni, "Impedance biosensor for peanut protein Ara h 1," Analytical Chemistry, vol. 80, no. 23, pp. 9157-9161, 2008.

[41] Y. G. Lee and K. U. S. Chang, "Application of a flow type quartz crystal microbalance immunosensor for real time determination of cattle bovine ephemeral fever virus in liquid," Talanta, vol. 65, no. 5, pp. 1335-1342, 2005.

[42] T. T. N. Lien, T. D. Lam, V. T. H. An et al., "Multi-wall carbon nanotubes (MWCNTs)-doped polypyrrole DNA biosensor for label-free detection of genetically modified organisms by QCM and EIS,” Talanta, vol. 80, no. 3, pp. 1164-1169, 2010. 

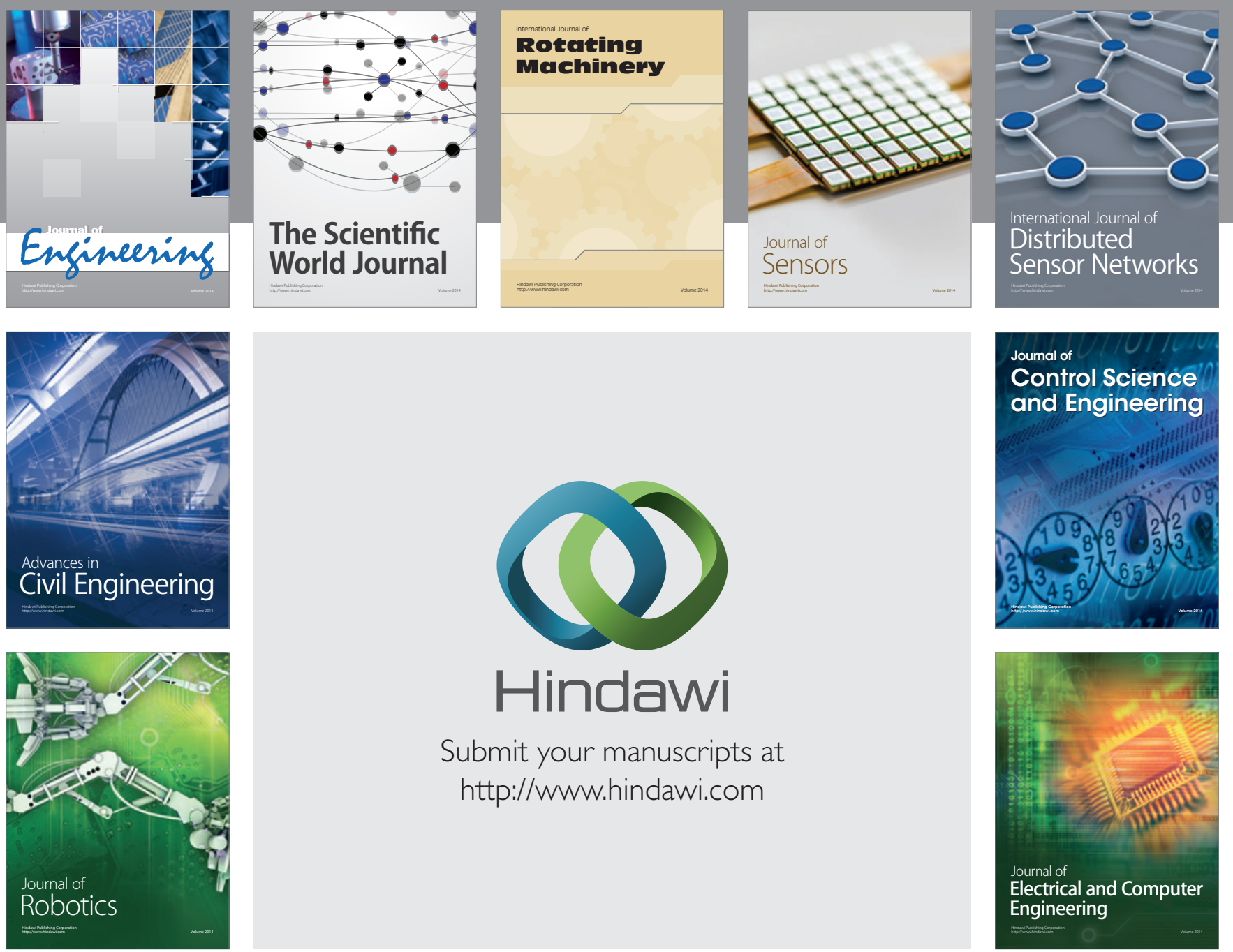

Submit your manuscripts at

http://www.hindawi.com
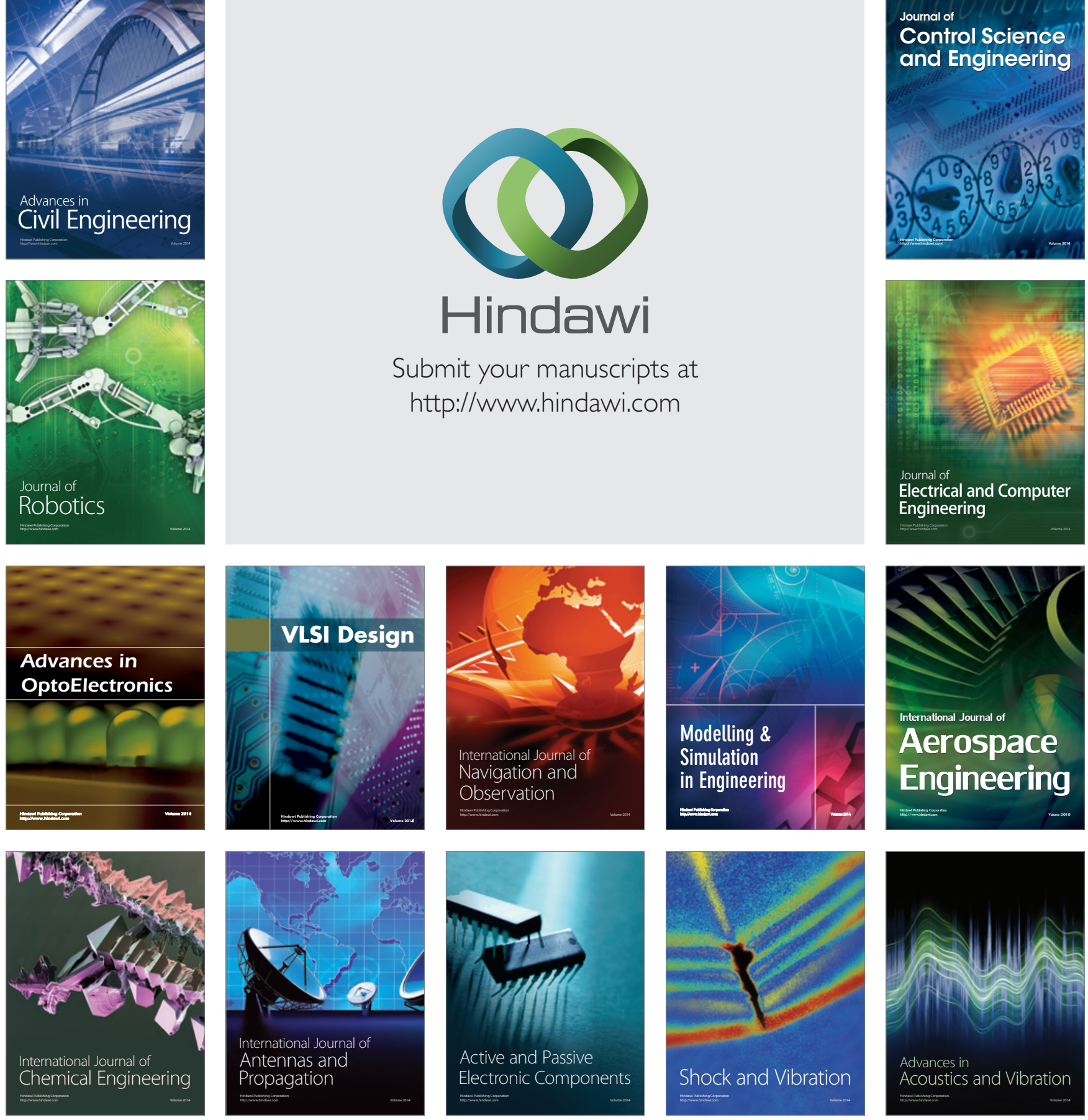